\title{
EXPERIMENTS AND CFD-MODELLING OF INSULATION DEBRIS TRANSPORT PHENOMENA IN WATER FLOW
}

\author{
Eckhard Krepper, Gregory Cartland-Glover, Alexander Grahn, Frank-Peter Weiss
}

\author{
Forschungszentrum Dresden-Rossendorf, Institute of Safety Research, \\ Germany-01328 Dresden, Bautzner Landstraße 128, www.fzd.de \\ E.Krepper@fzd.de
}

Sören Alt, Rainer Hampel, Wolfgang Kästner, Andrè Seeliger

University of Applied Sciences Zittau/Görlitz (FH),, Germany-02763 Zittau, Theodor-Körner-Allee 16; www.hs-zigr.de

\begin{abstract}
:
The investigation of insulation debris generation, transport and sedimentation becomes important with regard to reactor safety research for PWR and BWR, when considering the long-term behavior of emergency core cooling systems during all types of loss of coolant accidents (LOCA). The insulation debris released near the break during a LOCA incident consists of a mixture of disparate particle population that varies with size, shape, consistency and other properties. Some fractions of the released insulation debris can be transported into the reactor sump, where it may perturb/impinge on the emergency core cooling systems.
\end{abstract}

Open questions of generic interest are the sedimentation of the insulation debris in a water pool, its possible re-suspension and transport in the sump water flow and the particle load on strainers and corresponding pressure drop. A joint research project on such questions is being performed in cooperation between the University of Applied Sciences Zittau/Görlitz and the Forschungszentrum Dresden-Rossendorf. The project deals with the experimental investigation of particle transport phenomena in coolant flow and the development of CFD models for its description. While the experiments are performed at the University at Zittau/Görlitz, the theoretical modeling efforts are concentrated at Forschungszentrum Dresden-Rossendorf.

In the current paper the basic concepts for CFD modeling are described and feasibility studies including the conceptual design of the experiments are presented.

\section{INTRODUCTION}

In 1992, a safety relief valve inadvertently opened on a steam-line in the Barsebäck-2 nuclear power plant in Sweden. The steam jet stripped fibrous insulation from the adjacent piping systems. Part of the insulation debris was transported to the wetwell pool and this debris clogged the intact strainers of the drywell spray system about one hour after the start of the incident. Although the incident in itself had no serious consequences, it revealed a weakness in the defense-in-depth concept, which under other circumstances could have led to the emergency core cooling system (ECCS) failing to provide recirculation water to the core.

Research and development efforts of varying degrees of intensity were launched in many countries. The corresponding knowledge bases were updated several times and several workshops were performed (see OECD reports in the references). The international activities were especially summarized in the report NUREG/CR-6808 (2003) of the USNRC. A model of fiber release under the influence of a jet, an empirical equation for the difference pressure at the sieve dependent on the fiber load and the respective results of specifically designed material loadings experiments were presented. All these activities reflect in most cases the view of regulators and utilities. The current paper reports about efforts to investigate the problem on more generic level, particularly with the aim of CFD model development. 


\section{JOINT RESEARCH PROJECT}

A joint research project performed in cooperation between the University of Applied Science Zittau/Görlitz and Forschungszentrum Dresden-Rossendorf deals with the experimental investigation of particle transport phenomena in coolant flow and the development of CFD models for its simulation. The experiments are performed at the University Zittau/Görlitz and are mainly based on high-speed video observation and on Laser Doppler Velocimetry (LDV) as well as Particle Image Velocimetry (PIV). The theoretical work is concentrated at Forschungszentrum Dresden-Rossendorf. CFD models are developed, implemented in the CFD code ANSYS CFX and tested against experiments.

The main topics of the project are:

- Primary particle constitution: Experiments are performed to blast blocks of insulation material by steam under the thermal hydraulic conditions to be expected during a LOCA incident (i.e. at pressures up to $11 \mathrm{MPa}$ ). The material obtained by this method is then used as raw material for further experiments.

- Transport behavior of fibers: The transport behavior of the steam-blasted material is investigated in a water column by optical high-speed video techniques. The sinking velocities of the fibers are then used to derive the drag coefficients and other physical properties of the modeled fiber phase. This procedure is necessary for the implementation of an adequate CFD simulation.

- Transport of fibers in a turbulent water flow: For these investigations, a narrow channel set-up with a racetrack type configuration was used where well-defined flow boundary conditions were established. Laser PIV measurements and high-speed video were used for the investigation of the water flow-field and the fiber distribution. Besides the drag acting on the particles, the turbulent dispersion force plays an important role in determining the momentum exchanged between the water and the fibrous phase.

- Deposition and re-suspension of fibers: The deposition and re-suspension behavior at low velocities was investigated by the same techniques in the narrow racetrack channel. Except that, obstacles were inserted into the channel to change locally the flow regime. The experiments are designed to work with laser PIV measurement and high-speed video. CFD approaches consider the influence of the fiber material on the mixture viscosity and the dispersion coefficient on the transport of the solids.

- Behavior of a plunging jet in a large pool: By using high-speed video and laser (LDA and PIV) measurements, the progression of the momentum by the jet in the pool is investigated. Of special importance is the role that entrained gaseous bubbles play on disturbing the fluid and potentially influencing the fiber sedimentation and resuspension.

- Effect of strainers: A test rig was used to study the influence of the insulation material loading on the pressure difference over the strainers. A CFD model was developed that uses the approach of a porous body. Correlations from the filter theory known in chemical engineering are adapted to the experiments and are used to model the flow resistance depending on the particle load. This concept also enabled the simulation of a partially blocked strainer.

\section{SUBMERGED FIBER MODELS}

\subsection{General concepts}

The aim of the numerical simulations used in this study is to determine how and where mineral wool fibers are deposited within certain geometries, in this case, the sump of a containment vessel. Since the momentum transport in the liquid flow plays an important role, the problem is clearly a threedimensional problem that has to be solved by applying multiphasic computational fluid dynamic (CFD) methods. Such multiphasic codes resolve the conservation equations for mass, momentum and energy and they are distinguished by the different approaches and strategies used in describing the 
physical closure models. For the solution of the described task, two fundamentally different reference frames can be used: Eulerian-Lagrangian or Eulerian-Eulerian frame.

The Eulerian-Lagrangian approach treats the dispersed phase by resolving the Lagrangian equation of motion for each particle, which moves through a continuous fluid that is resolved by the Eulerian Navier-Stokes equations. The particles are defined as having a certain mass, which imposes the momentum exchanged at the point locations of the particles. The flow field acts on each particle and influences the particle path. The particles in turn affect the turbulence quantities of the flow. Particle spectra can define the different particles found in the steam-blasted material. Specific physical phenomena can be simulated using models for the particle reflection and the sedimentation at walls.

The Euler/Euler approach assumes that at least two fluids are continuously penetrating each other. The volume fraction of the fluids in each cell sums to unity. For each fluid, the full set of conservation equations is solved. Therefore, each fluid has a different velocity field. The mechanisms of the interaction of the fluids are the momentum transfer modeled by the flow resistance, the mass transfer modeled by phase change and the energy transfer modeled by heat conduction. Whereas, the two latter interactions in the present problem are not relevant, the flow resistance is essential for the description of debris transport.

Compared to the Euler/Euler approach the Euler/Lagrangian approach requires a higher numerical effort, which can limit their applicability to the practical question of interest here.

\subsection{Force Closure Models in the Euler/Euler approach}

The particle transport using the Euler/Euler approach is described by the exchange of momentum between the two phases. For the case of dispersed spherical bubbles or spherical particles moving in a continuous fluid, the interacting forces between the two phases have the principle form:

$$
\mathbf{F}_{D}=\frac{1}{2} n_{d} \rho_{c} A C_{D}\left|\mathbf{U}_{r e l}\right| \mathbf{U}_{r e l}
$$

where $n_{d}$ is the particle number density, $\rho_{\mathrm{C}}$ the liquid density, A the cross sectional area of the particle in the flow direction, $U_{\text {rel }}$ the relative velocity between the phases, and $C_{D}$ the drag coefficient.

The drag coefficient depends on the Reynolds Number, which is defined as

$$
\operatorname{Re}=\frac{\rho\left|\mathbf{U}_{r e l}\right| d}{\mu}
$$

with $\mu$ as the dynamic liquid viscosity.

For low velocities and Reynolds Numbers $<<1$ the viscosity effects are dominating. The regime is designated as Stokes-Regime and $C_{D}=24 / \mathrm{Re}$. For high velocities $\left(1000<\operatorname{Re}<1 . .2 .10^{5}\right)$ the inertia effects are dominating and $C_{D}=0.44$. In the transition region $(0.1<\operatorname{Re}<1000)$, both effects are of the same order of magnitude. In the literature, many correlations of the drag coefficient have been published. These correlations consider the eccentricity of particles (e.g. Haider and Levenspiel (1989), Salman and Verba (1988)). Turney et al. (1995) describe the drag for rod like particles. Lots of correlations fitted to experiments have in general the form which Schiller and Naumann (1933) gives for spherical particles:

$$
C_{D}=\max \left[\frac{24}{\operatorname{Re}}\left(1+0.15 \operatorname{Re}^{0.687}\right), 0.44\right]
$$

In the current study, a virtual particle is defined as a small ball of wool fibers that mostly consists of water. This is correct as the water in the insulation wool ball moves with the virtual particle velocity. This is due to entrapment of the water and local forces binding the water to the particles. Therefore, the virtual particle density, $\rho_{F}$, found here is close to that of water (i.e. $1000 \mathrm{~kg} \mathrm{~m}^{-3}$ ), whereas the density of real dry fibers $\rho_{P}$ amounts to about $2800 \mathrm{~kg} \mathrm{~m}^{-3}$. The density difference of water and fibers in the gravity field results in the buoyancy force $F_{B}$ : 


$$
F_{B}=n_{d} g V_{F}\left(\rho_{F}-\rho_{c}\right)
$$

with the virtual particle volume $V_{F}$. The equality of buoyancy and drag forces yields the sinking velocity $U_{S}$ :

$$
U_{S}=\sqrt{\frac{4}{3} g \frac{\rho_{F}-\rho_{c}}{\rho_{c}} d_{F} \frac{1}{C_{D}}}
$$

with the virtual particle diameter, $d_{F}$. The share of fibers, $\alpha_{F}$, in the virtual particle can be calculated by:

$$
\alpha_{F}=\frac{\rho_{F}-\rho_{c}}{\rho_{P}-\rho_{c}}
$$

\subsection{Turbulent Dispersion}

When the simulation of the motion of buoyant particles only considers the drag force described in section 3.2, this results in the settling of the virtual particles to the lower boundary. The observation of fibers in a turbulent water flow however shows suspending and gliding fibers. In the current work the interaction of the turbulent water flow and the fibers was considered by a turbulent dispersion force. This force was originally developed to obtain a closure model for the Reynolds stresses in terms of the $\mathrm{k}-\varepsilon$ turbulence model and the transport of the particles in the continuous phase. It is based on the spatial gradient of the parameter characterizing local dispersed phase (either the volume fraction or average mass density). The coefficient was derived from the integrating the fluctuating terms of the instantaneous particle transport equation along the particles trajectory. It was assumed that the autocorrelation of the turbulence is an exponential function of the Lagrangian turbulence time, $\tau_{\mathrm{c}}$. This lead to equation (7) as the limit of the integral with respect to time is increased to infinity. The fluctuating turbulent velocities of the continuous phase can be obtained from the turbulent kinetic energy (see Moraga et al., 2003, Hwang, 2006).

$$
-\mathbf{F}_{T D, d}=-\rho_{d} \frac{\tau_{c}}{\tau_{d}}\left(\frac{\tau_{c}}{\tau_{c}+\tau_{d}}\right)\left\langle u_{c}^{\prime} u_{c}^{\prime}\right\rangle \nabla \Phi=-C_{T D} \rho_{d} k_{c} \nabla \Phi
$$

A Favre-Averaged form of the turbulent dispersion force was developed to exploit the convenience using mass-weighted averages to express the ensemble averages of the flow variables (Burns et al. 2004). This convenience is based on fewer terms in the continuity equations and fewer terms that require direct modeling:

$$
-\mathbf{F}_{T D, d}=-C_{T D} \frac{3 C_{D} \nu_{t c}}{4 d_{F} S c} \rho_{C}\left|\mathbf{U}_{r e l}\right| \nabla \Phi
$$

$C_{T D}$ is a proportionality coefficient further discussed in section 4.3. $C_{D}$ is the drag coefficient, $v_{t c}$ is the eddy viscosity of the water phase, $d_{F}$ the virtual particle diameter, $S c$ the Schmidt number and $\underline{\mathrm{U}}_{r e l}$ is the relative velocity vector between the virtual particle and the water phase.

\subsection{Modeling of Fiber Agglomeration and Re-Suspension}

In applying the turbulent dispersion model, it is important to understand how the various closure models are used in the definition of the fluid-particle phase interactions, which affect the resultant force.

The closure models of interest are the correlations for the mixture viscosity and drag coefficient. The correlation of the drag coefficient to Reynolds number, which defines the relaxation time of the particle and the response that the particles have to the turbulent eddies, whilst the mixture viscosity can modify the viscous stresses that the particle experiences and thus the spread of the particles caused by the velocity gradient. 
Therefore, to assess the variation of viscosity with the volume fraction of dispersed phase, a number of models based on the product of a relative viscosity and the liquid phase viscosity (eq. 9) have been developed. Many examples of this product, which is generally known as a mixture viscosity have been reported, where the relative viscosity is based on the Maron-Pierce equation (Maron and Pierce (1956)) or based on the effective viscosity of Einstein as reported by Batchelor (1977). Krieger et al. (1959) also developed a similar correlation, (eq. 10), which has been widely used. Note that $[\mu]$ is the intrinsic viscosity, which was defined as 2.5 for spheres.

$$
\begin{gathered}
\mu_{m}=\mu_{r} \mu_{c} \\
\mu_{r}=\left[1-\frac{\Phi}{\Phi_{m}}\right]^{-[\mu] \phi_{m}} \\
\mu_{r}=1+[\mu] \Phi+k_{h y d} \Phi^{2}
\end{gathered}
$$

Batchelor (1977) proposed (eq. 11), which was used by Xu et al. (2005) in the modeling of particle transport. The modification is the result of the addition of the second order term to the equation to represent the influence of the bulk stress. The coefficient of the second order term, $k_{h y d}$, is dependent on the local hydrodynamic conditions, the rheology of the fluid mixture, uniformity of particle probability distribution, and isotropy of the turbulence. $k_{h y d}$ was defined as 6.2 for uniform distributions in a Newtonian mixture. Two values were expected for non-uniform distributions; $k_{\text {hyd }}$ was 7.6 for a purely straining isotropic flow, however no value was reported for simple shearing nonisotropic flows (see Batchelor (1977).

The following empirical model for the viscosity is used to correlate the volume fraction to the relative viscosity:

$$
\mu_{r}=1+\left\{\begin{array}{cr}
0 & \Phi \leq 0.6 \\
\Phi^{3} \cdot 10^{4} & \Phi \geq 0.6
\end{array}\right.
$$

\section{MODEL VALIDATION BY MEANS OF EXPERIMENTS}

\subsection{Determination of the drag coefficient}

To determine the drag coefficient of the particles, the motion of settling particles were studied in the test rig "column". The particles were obtained from steam-blasting experiments and they are inserted into a Plexiglas column. The column has a height of $3 \mathrm{~m}$, a width of $0.5 \mathrm{~m}$ and a depth of $0.1 \mathrm{~m}$. A numerical evaluation of the distribution of sinking velocities was determined using high-speed video (Fig. 1).

A distribution of sinking velocities was found (right part of Fig. 1) along with a distribution of the estimated particle size below. The particles consist of an agglomeration of smaller particles of different sizes, densities and shape. Larger objects are disintegrated under the influence of the shear stresses and turbulence from the surrounding liquid. The turbulent wake of the larger particle agglomerations causes breakage of the following agglomerations that result in the generation of finer particle fractions.

Extensive tests have shown, that the sinking behavior not only depends on the insulation material itself, but also on the wettability of the fibers, which is influenced by the age, the kind of drying and the hydrophobic properties and finally on the preparation procedure of the material.

The sinking velocities for the MD-2 type were measured at the facility in Zittau. Comparable velocities of other materials published in the NUREG/CR-6808 were found. A dependency of the sinking velocity on the fragmentation procedure for MD-2 fibers was observed. The fragmentation by steam performed in the facility in Zittau results in sinking velocities of $0.005-0.12 \mathrm{~m} / \mathrm{s}$ while the manual fragmentation results in larger particles and larger sinking velocities of $0.01-0.2 \mathrm{~m} / \mathrm{s}$. 

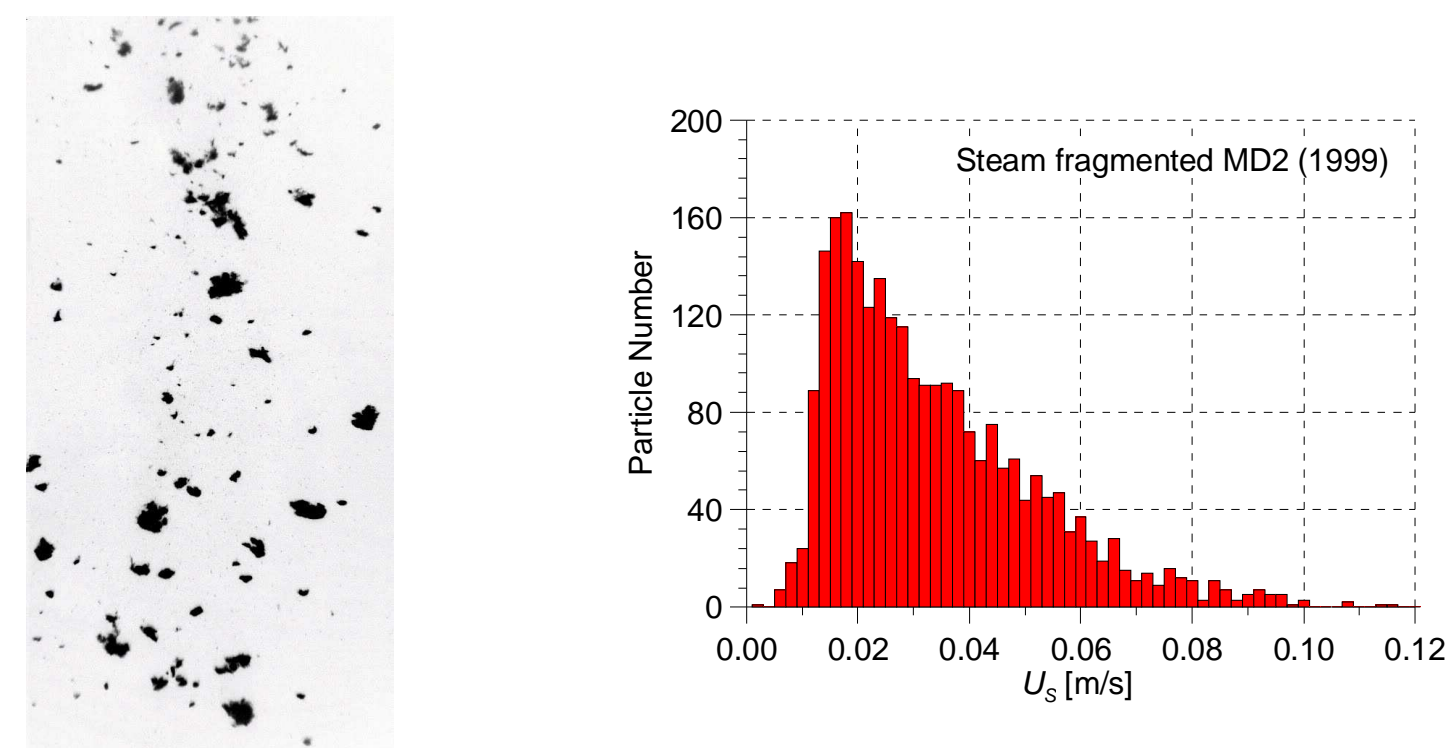

Fig.1: Photography of sinking fibers (left side) and assessed distribution of sinking velocities measured in the test rig "column" investigating the material MD2

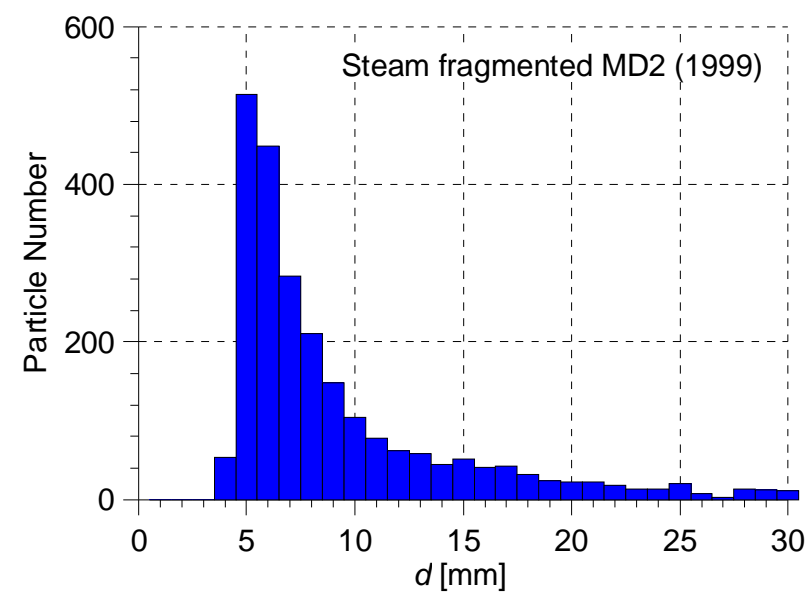

Fig. 2: Measured particle size distribution

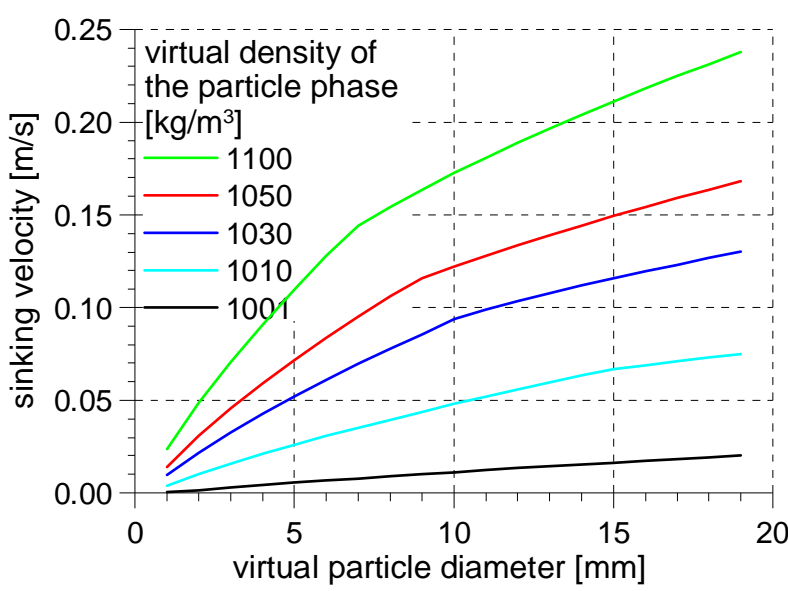

Fig. 3: Dependence of the sinking velocity on the virtual particle density and the virtual particle diameter

The diagram shown in Fig. 3 presents the results of eq. (3). Fig. 3 considers the fact that the drag coefficient, $C_{D}$, is dependent on the Re-Number, which in turn is dependent on the terminal velocity, $U_{S}$. Thus, eq. (3) must be resolved iteratively in order to obtain consistent values for the terminal velocity with respect to the particle size and density.

The example material shown in Fig. 1 has an average sinking velocity of $0.03 \mathrm{~m} \mathrm{~s}^{-1}$. Assuming a virtual density of $1020 \mathrm{~kg} \mathrm{~m}^{-3}$, a virtual particle diameter of $d_{F}=5 \mathrm{~mm}$ and a drag coefficient of $C_{D}$ $=0.9$, the same sinking velocity can be calculated according eq. (5). The assumed virtual particle size corresponds to typical values from such observations (see Fig. 2). The density of dry fibers was 2800 $\mathrm{kg} \mathrm{m}^{-3}$ that gives the dry fiber share in the virtual particle of $\alpha_{F}=0.0111$ (see eq. 6).

\subsection{Investigation of a turbulent water flow}

The transport properties of fibers in a turbulent water flow is investigated experimentally in a flat race track type channel with a width of $0.1 \mathrm{~m}$, a depth of $1.2 \mathrm{~m}$ and straight sections with a length of $5 \mathrm{~m}$ (see Fig. 4). The bends have a radius of $0.5 \mathrm{~m}$. The water flow is driven by two slow moving pumps 
driving the liquid at velocities between 0.01 and $1.0 \mathrm{~m} \mathrm{~s}^{-1}$. The fiber distribution and the water velocity field were observed by using high-speed video and by Laser based PIV.

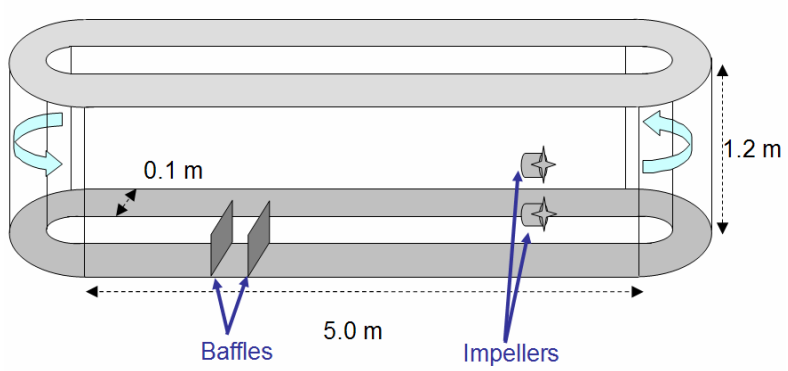

Fig. 4: Channel for investigation of the behavior of fibers in a turbulent flow

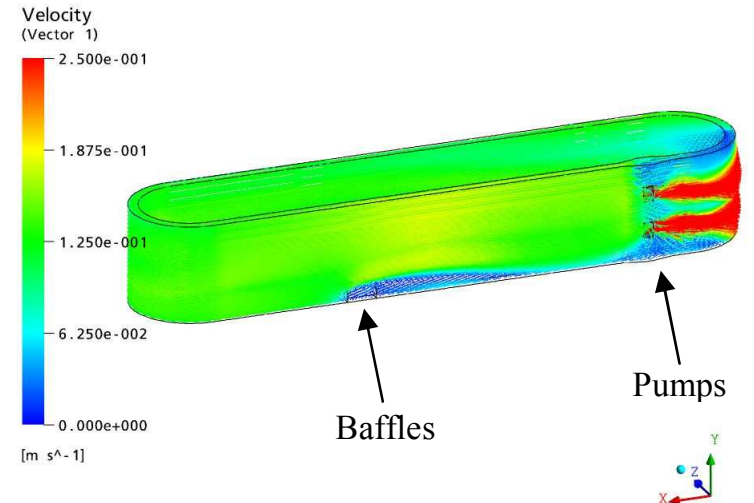

Fig. 5: Calculated velocity field with baffle plates

To provoke a flow disturbance the channel was equipped with 0.1 and $0.2 \mathrm{~m}$ high baffles separated by a distance of $0.3 \mathrm{~m}$ (see Figs. 4 and 5). The flow field was measured by PIV laser techniques.

The observations of the experiments with fiber flow in the circulating water showed that at higher circulation velocities (ca. $>0.5 \mathrm{~m} / \mathrm{s}$ ) the fiber sinking is replaced by a horizontal transport of the fibers. This phenomenon can be simulated considering the turbulence dispersion force (see section 3.3).

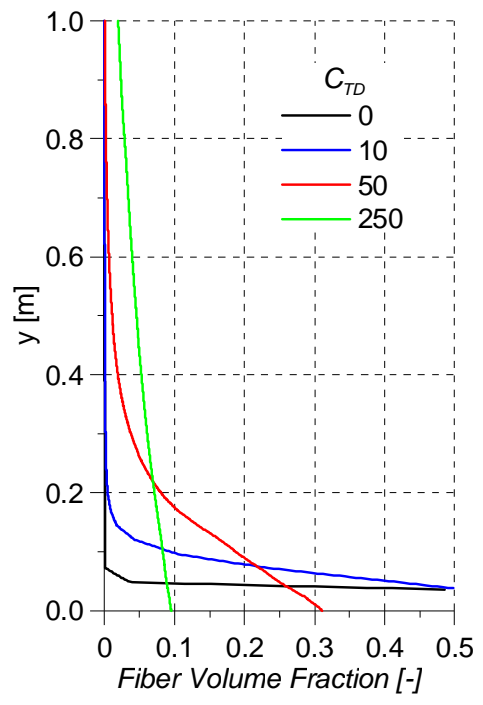

Fig. 6: Calculated dependence of the vertical fiber volume fraction profile on $C_{T D}$ for whole channel simulations with a local mean horizontal velocity of $0.5 \mathrm{~m} \mathrm{~s}^{-1}$

Almost the whole particle phase is deposited at the bottom in simulations that do not consider the turbulent dispersion force. For a virtual particle, density of $\rho_{F}=1030 \mathrm{~kg} \mathrm{~m}^{-3}$, which results in a sinking velocity of $U_{S}=0.05 \mathrm{~m} \mathrm{~s}^{-1}$ the buoyancy force $F_{B}$ (see eq. 4), is estimated to be between 10 and $100 \mathrm{~kg} \mathrm{~m}^{-2} \mathrm{~s}^{-2}$. CFD simulations of the channel for the case of an averaged water velocity of about $0.5 \mathrm{~m} \mathrm{~s}^{-1}$ resulted in an averaged turbulence viscosity of the order of $0.25 \mathrm{~kg} \mathrm{~m}^{-1} \mathrm{~s}^{-1}$. Keeping in mind the drag coefficient for the virtual particle flow in water of ca. 0.7 and assuming reasonable values for the volume fraction gradient of ca. $0.1 \mathrm{~m}^{-1}$ the turbulent dispersion force (see eq. 8) becomes comparable to the buoyancy force $F_{B}$ with a coefficient $C_{T D}$ in the order of ca. 100. Typical values of $C_{T D}$ were found to be of the order of 1 for gas bubbles. In the literature $C_{T D}$ was proposed as 500 for smaller diameter particles when the ratio of the particle relaxation time, $\tau \mathrm{d}$, to $\tau \mathrm{c}$ is small (see Moraga 
et al., 2003, Hwang, 2006). By means of the experiments hints for a reasonable value of $C_{T D}$ can be found by determining the vertical fiber concentration profile. The dependency of the vertical profile of the fiber volume fraction on the value of the turbulent dispersion force was shown by calculations. Fig. 6 presents the vertical profiles for different values of the coefficient $C_{T D}$. Corresponding experiments that measure the vertical profile of the fiber volume fraction for different water velocities are in preparation.

\subsection{Investigation of the agglomeration and re-suspension behavior of the fibers}

For the investigation of the agglomeration and re-suspension properties of fibers, the region between the baffles was observed. The obstacles in the straight sections not only disturb the motion of the liquid but also promote deposition of the particles.

The experiments revealed that the fibers agglomerate at a critical fiber volume fraction, which is manifested by a strong increase of viscosity. In addition, the fibers are deposited at the bottom of the channel below a critical water velocity of about $0.1 \mathrm{~m} \mathrm{~s}^{-1}$, particularly at locations downstream of the obstacles. Increasing the water velocity beyond $0.1 \mathrm{~m} \mathrm{~s}^{-1}$ causes the fibers to be mobilized again.

The application of the Eulerian-Eulerian approach for the sedimentation and re-suspension of the fibers involved the use of volume fraction dependent viscosities (see section 3.4) and the turbulent dispersion force (section 3.3).

A feasibility study of the accumulation of fibers between two dams arranged at a distance of $0.3 \mathrm{~m}$ and having a height of $0.1 \mathrm{~m}$ investigated in the experiment (Fig. 7) and compared to a transient CFX calculation (Fig. 8).

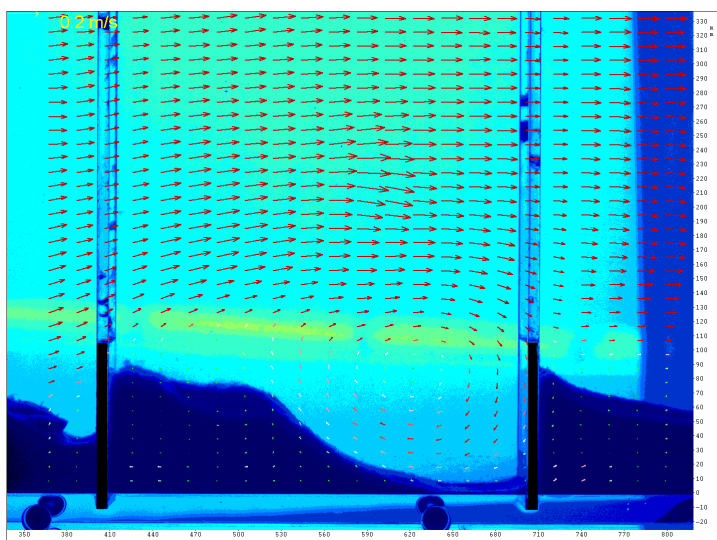

Fig. 7: Laser PIV measurements of the water velocity field and video observations of the fiber distribution between two baffles

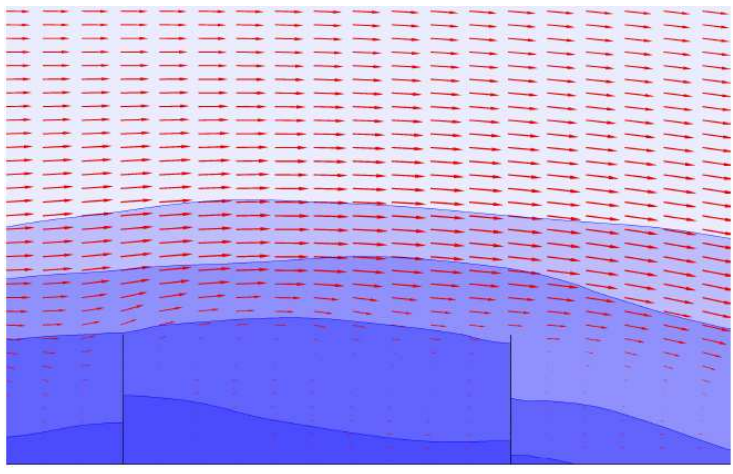

Fig. 8: Calculated water velocity field and fiber distribution for the viscosity model of equation

(11)

The results show that the CFD code at least is able to simulate the qualitative behavior of the fibrous flow. Further investigations are underway to provide a deeper analysis of these experiments. The evaluation of area fractions of the vertical observation plane occupied by the particles, which are gained from video observations of the fibrous volume fraction, can be interpreted as a measure for the accumulated fiber mass. Neglecting the extension in the channel depth, these measurements will yield the necessary information in order to improve the physical representation of the solid phase with regard to the solid build-up observed in the experiments.

\section{INVESTIGATION OF PLUNGING JET PHENOMENA}

According to the considered scenario, the water ejected by the anticipated break falls several meters on to the sump water surface. On its way, the jet is mixed with air. Furthermore, the impinging jet will entrain air bubbles. The momentum impact of the jet on the water flow field will be smeared out with growing penetration depth. The entrained gaseous bubbles will rise and have an additional influence 
on the flow field. The jet-induced flow in the sump will sensitively influence the fiber transport in the sump. The questions in this concern are how the fiber transport in the sump is influenced by the jet and where in the sump the fibers preferably are deposited.

To investigate the influence of a plunging jet experiments in a water tank with dimensions of about $1 * 1 * 1 \mathrm{~m}$ was prepared. As a first step the jet of water with the entrainment of air at ambient conditions was investigated. The fluid flow field is measured by laser PIV measurements. The gas flow is observed by high-speed video. CFD calculations are performed to prepare the experiments.

During the presented CFD calculations, the phenomenon of the air entrainment by the jet was not modeled but given as an inlet condition. Therefore, published correlations for the air entrainment are applied, as the aim of the calculations is the determination of the flow field in the volume.

Correlations on gas entrainment at a plunging jet were published by Bin (1993), Bonetto et al. (1993), Cummings et al. (1997a and b) and Iguchi et al. (1998). Bin (1993) reports the following empirical correlation. A water volume flow $Q_{W}$ hit from a height $H$ with the diameter $d_{i}$ and the velocity $U_{O F}$ at a water surface entrains the volume flow $Q_{G}$ of gaseous bubbles:

$$
\begin{gathered}
Q_{G}=0.04 Q_{W} F r^{0.28}\left(\frac{H}{d_{i}}\right)^{0.4} \\
F r=\frac{U_{O F}^{2}}{g d_{i}}
\end{gathered}
$$

Fr is the Froude Number:

The maximum penetration depth $Z_{P, B}$ of bubbles is given by

$$
Z_{P, B}=0.42 U_{O F}^{4 / 3} d_{i} Q_{G}^{-1 / 4}
$$

Assuming a jet inlet velocity of $3 \mathrm{~m} / \mathrm{s}$ and an impingement diameter on the surface of $0.05 \mathrm{~m}$ according to equation (13) an air entrainment having a volume flow $Q_{G}$ of ca. $0.2 Q_{W}$ has to be expected. The corresponding maximum gas penetration depth was calculated by equation (15) to be ca. $0.5 \mathrm{~m}$.

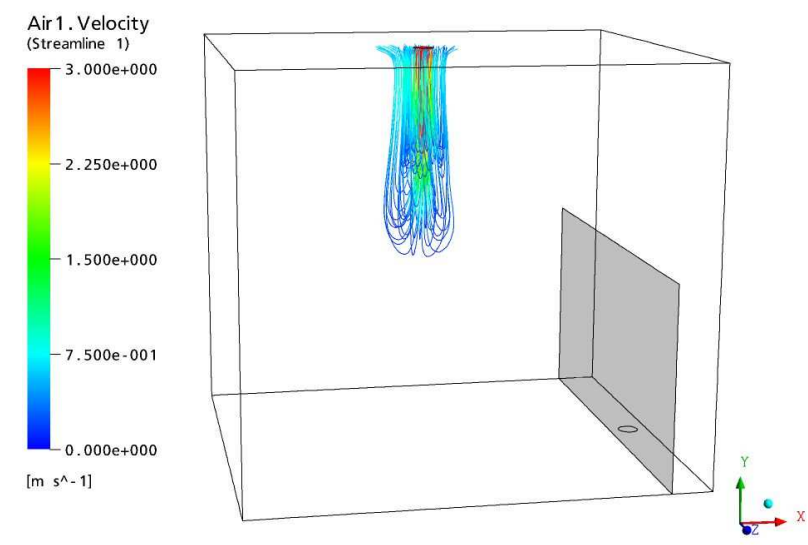

Fig. 9: CFD simulation of the jet experiment

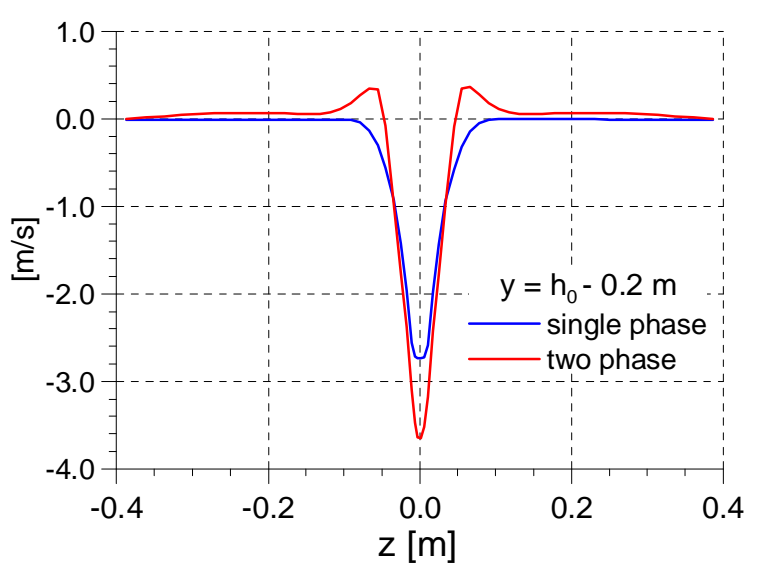

Fig. 10: Influence of the air entrainment on the liquid on the liquid velocity profile

Fig. 9 shows the results of CFD calculations. At the inlet, a water flow of $3 \mathrm{~m} / \mathrm{s}$ with a gas content of 0.2 is simulated. The water is drained out of the tank via the outlet at the bottom. The entrained gas leaves the tank via the water surface. Fig 10 shows the gas streamlines calculated according to the gas velocity field. The maximum gas penetration depth is determined by the lowest point of the zero value of the vertical component of the gas velocity field. The value of ca. $0.5 \mathrm{~m}$ predicted by eq. (15) is confirmed by the CFD calculations. 
Fig. 10 presents the influence of the gas entrainment on the liquid velocity field near the jet. The entrained bubbles near the jet will rise and decrease the water velocity. The profiles $0.2 \mathrm{~m}$ below the water surface shown in Fig. 10 indicate an upward water flow near the jet. The streamlines of the water flow projected onto a plane located at the middle of the tank show, for the single-phase case, two vortices near the tank bottom (see Fig. 11). In the two-phase case, these vortices are shifted towards the upper regions (see Fig. 12).
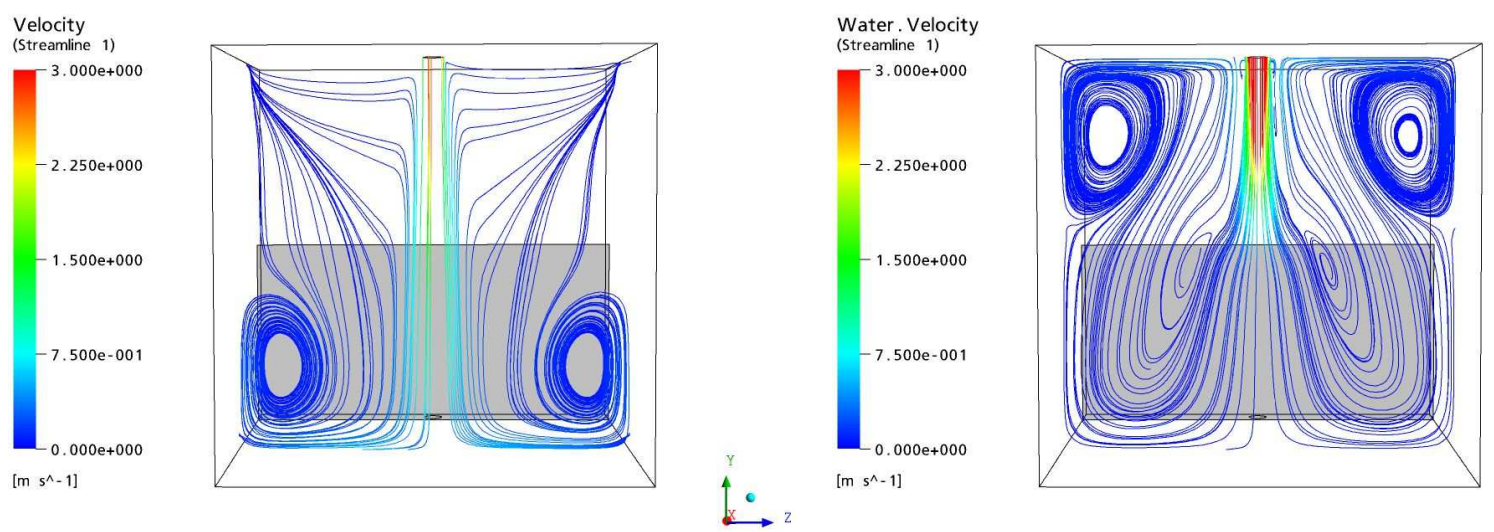

Fig. 12: Water streamlines considering the air

Fig. 11: Water streamlines neglecting the air entrainment

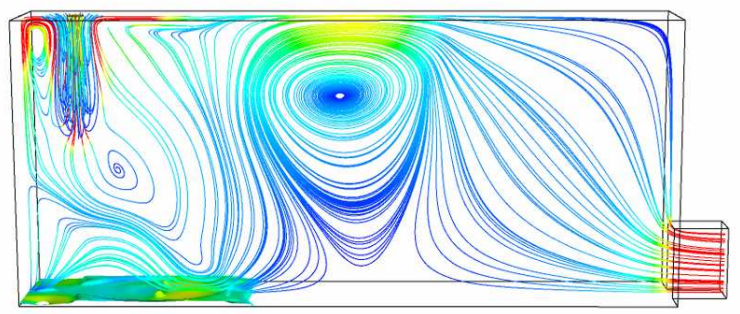

Fig. 13: Water flow field induced by the entrained air entrainment

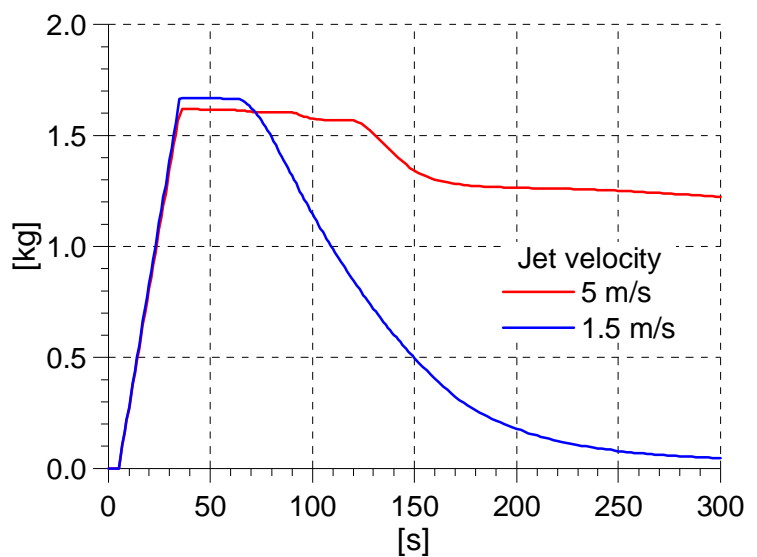

Fig. 14: Accumulated fiber mass dependent on the inlet velocity

The two phase flow behavior has remarkable consequences on the flow field observed in a larger geometry similar to a real reactor sump. During an additional experiment in Zittau the flow in a tank of a length of $6 \mathrm{~m}$, a depth of $1 \mathrm{~m}$ and a water height of $2.6 \mathrm{~m}$ was investigated (see Fig. 13). In preliminary CFD calculations the situation was investigated. Water was injected at the left side and correspondingly removed at the lower right side. During a certain time additional fibers were added to the injection. Air is entrained by the water jet and has an influence on the flow field. In the case of an inlet velocity of $5 \mathrm{~m} \mathrm{~s}^{-1}$ the entrained air reaches a depth of about $1.5 \mathrm{~m}$. Fig. 13 presents the water streamlines projected at the middle plane. During the water injection in the tank, a large swirl that rotates in the clockwise direction is established. The swirl moves the injected fibers backward to the region just below the water injection. Large amounts of fibers are accumulated in the swirl and fixed in the tank before they reach the outlet.

A different flow picture is found with a water injection velocity of only $1.5 \mathrm{~m} \mathrm{~s}^{-1}$. During this second case the same fiber mass was added. In this case the entrained air reaches a depth of only $0.7 \mathrm{~m}$. The large water swirl observed in the first case is not established in the second case. The fibers move directly to the outlet. Fig. 14 shows the integral fiber mass for these two cases. 
Further investigations can use the experience gained by these studies for the application of such models to real sump geometries. The preferred regions of fiber accumulation are dependent on the flow situation, which can be identified by such calculations. The modification of the flow field caused by changes to the geometrical construction e.g. by introduction of baffle plates etc. can also be investigated.

\section{SIMULATION OF STRAINERS}

Filter cakes composed of fibrous materials have two particular features: a) They are of very high porosity, and b), due to the deformability of the fibers, such cakes can be easily compressed under the action of fluid drag forces or an external compacting pressure. A semi-empirical model has been developed for calculating the pressure drop across beds of this class of materials as a function of superficial velocity and material properties (Grahn et al. 2006). It consists of a material equation:

$$
\varepsilon(p)=\varepsilon_{\text {min }}+\left(\varepsilon_{0}-\varepsilon_{\min }\right) e^{-C p^{D}}
$$

which describes the dependency of porosity on the compaction pressure $\mathrm{p}$, and a differential equation for the local pressure drop:

$$
\frac{d p}{d x}=f\left(U, U^{2}, \varepsilon(p)\right)
$$

An algorithm has been implemented, which solves the model equations by numerical integration. It yields pressure and porosity profiles along the compressed fiber bed as well as its streamwise thickness and the overall pressure drop, dp, Parameters $\varepsilon_{\min }, \varepsilon_{0}, C$ and $D$ of the material equation have been fitted to data from compaction pressure vs. porosity measurements. In the present state of the model, the transient pressure build-up can be simulated as well by specifying a non-zero mass fraction of insulation material for the inflow. The model was implemented into the CFD code ANSYS CFX, allowing for simulation of partially clogged strainers.

\begin{tabular}{|l|c|c|c|c|}
\hline \multicolumn{5}{|c|}{ Table 1: Experimental conditions } \\
\hline run & $\begin{array}{c}N_{S} \\
{\left[\mathrm{~kg} \mathrm{~m}^{-2}\right]}\end{array}$ & $\begin{array}{c}T \\
{\left[{ }^{\circ} \mathrm{C}\right]}\end{array}$ & $\begin{array}{c}\rho \\
{\left[\mathrm{kg} \mathrm{m}^{-3}\right]}\end{array}$ & $\begin{array}{c}\mu \\
{[\mathrm{mPa} \mathrm{s}]}\end{array}$ \\
\hline 1 & 6.01 & 44.6 & 990.4 & 0.601 \\
\hline 2 & 6.01 & 59.0 & 983.4 & 0.474 \\
\hline 3 & 3.87 & 58.9 & 983.8 & 0.475 \\
\hline 4 & 1.96 & 59.7 & 983.4 & 0.469 \\
\hline 5 & 0.32 & 59.7 & 983.4 & 0.469 \\
\hline
\end{tabular}

The pressure drop across the compressed fiber bed has been determined both numerically and experimentally as a function of superficial velocity. Moreover, experimental conditions, i.e. strainer mass load and fluid properties have been varied (Table 1). In Fig. 15 computed curves are compared to measured values. It can be seen, that numerical calculations reproduce measured pressure drops qualitatively and quantitatively well.

$N_{S}$ is the fiber load, $\rho$ the density and $\mu$ the fiber viscosity. Another phenomenon, which has been investigated, is the so-called thin-bed effect. It results from relatively small (as compared to fiber dimensions) granular particles that are deposited, either onto the outer (upstream) surface of the fiber bed or in between the fibers. They form layers of sludge with lower porosity and little compressibility, but result in a higher pressure-drop with the addition of each layer. Such layers act like a plug, imposing an additional external compacting pressure onto the fiber bed. Transient calculations have been performed to assess the influence of the penetration depth of particles on the overall pressure drop. The penetration depth depends on the nature and the magnitude of particle-fiber interaction. From the comparison of the different cases in Fig. 16 one can conclude that the additional modeling effort required for quantifying the particle-fiber interaction is not justified. 


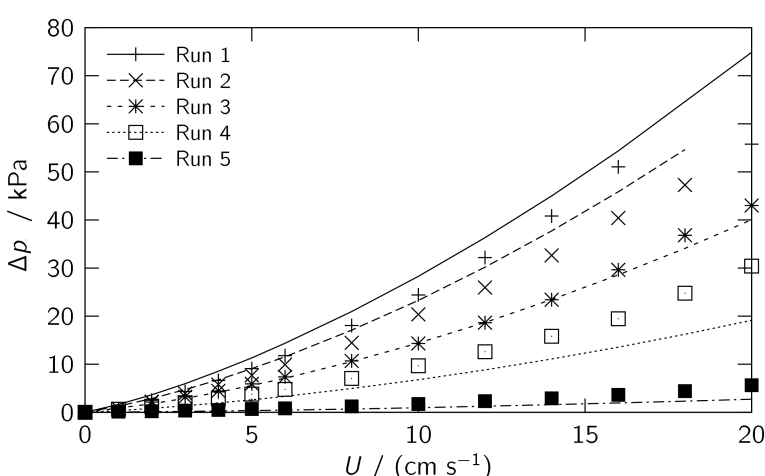

Fig. 15: Pressure drop across compressed fiber bed vs. superficial velocity at different experimental conditions (strainer mass load, fluid properties), experiments (points), computed profiles (lines)

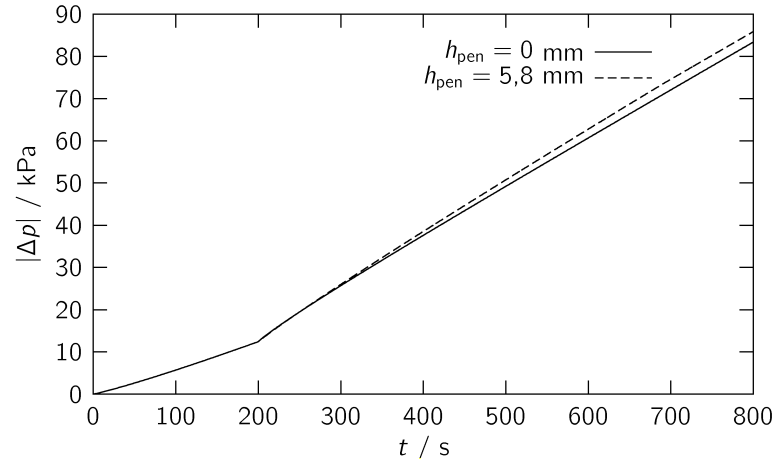

Fig. 16: Pressure drop buildup at composed beds; superficial velocity $U=6 \mathrm{~cm} / \mathrm{s}$, accumulation of fibers for $0<\mathrm{t}<200 \mathrm{~s}$, sludge particle deposition for $200 \mathrm{~s}<\mathrm{t}<800 \mathrm{~s}$, different penetration depths $h_{p e n}$

\section{SUMMARY AND NEXT STEPS}

The project work is still underway. Several model concepts were presented to describe the whole process of fiber transport applying CFD methods. The presented results show that the intended model approaches are feasible for the simulation of the interested phenomena. The paper shows the correct qualitative behavior of the solutions and the correct dependency of model parameters. The aim of the work was the preparation of the necessary experiments to adjust the free parameters. The developed models including the adjusted model parameters will enable the answering of many practical questions relating to the strainer clogging issue.

\section{ACKNOWLEDGMENTS}

The reported investigations are funded by the German Federal Ministry of Economy and Technology under contract No. 1501270 and 1501307.

\section{NOMENCLATURE}

\begin{tabular}{|c|c|c|}
\hline Sign & Unit & Denomination \\
\hline$A$ & $\mathrm{~m}^{2}$ & cross section area \\
\hline$C$ & $\left(\mathrm{~kg} \mathrm{~m}^{-1} \mathrm{~s}^{-2}\right)^{-\mathrm{D}}$ & $\begin{array}{l}\text { experimental determined coefficient for the fibre compaction pressure porosity } \\
\text { dependency }\end{array}$ \\
\hline$C_{\mathrm{D}}$ & - & drag coefficient \\
\hline$C_{\mathrm{TD}}$ & - & turbulence dispersion coefficient \\
\hline$D$ & - & $\begin{array}{l}\text { experimentally determined index for the fibre compaction pressure porosity } \\
\text { dependency }\end{array}$ \\
\hline$d_{\mathrm{F}}$ & $\mathrm{m}$ & virtual diameter \\
\hline$d_{\mathrm{i}}$ & $\mathrm{m}$ & impingement diameter \\
\hline$\Delta$ & - & difference \\
\hline $\mathbf{F}_{\mathrm{B}}$ & $\mathrm{kg} \mathrm{m}^{-2} \mathrm{~s}^{-2}$ & buoyancy force \\
\hline $\mathbf{F}_{\mathrm{D}}$ & $\mathrm{kg} \mathrm{m}^{-2} \mathrm{~s}^{-2}$ & drag force \\
\hline $\mathbf{F}_{\mathrm{TD}, \mathrm{d}}$ & $\mathrm{kg} \mathrm{m}^{-2} \mathrm{~s}^{-2}$ & turbulent dispersion force acting on the dispersed phase \\
\hline$F r$ & - & Froude number \\
\hline
\end{tabular}




\begin{tabular}{|c|c|c|}
\hline$g$ & $\mathrm{~m} \mathrm{~s}^{-2}$ & acceleration due to gravity \\
\hline$H$ & $\mathrm{~m}$ & height of jet \\
\hline$h_{\text {pen }}$ & $\mathrm{m}$ & penetration depth \\
\hline$i, j, k$ & - & numeric indexes \\
\hline$k_{\text {hyd }}$ & - & flow dependent coefficient \\
\hline$k_{\mathrm{c}}$ & $\mathrm{m}^{2} \mathrm{~s}^{-2}$ & continuous phase turbulent kinetic energy \\
\hline$N_{\mathrm{s}}$ & $\mathrm{kg} \mathrm{m}^{-2}$ & fibre mass loading \\
\hline$n_{\mathrm{d}}$ & - & particle number density \\
\hline$p$ & $\mathrm{~kg} \mathrm{~m}^{-1} \mathrm{~s}^{-2}$ & fluid pressure \\
\hline$Q_{\mathrm{G}}$ & $\mathrm{m}^{3} \mathrm{~s}^{-1}$ & volumetric flow of entrained gas bubbles \\
\hline$Q_{\mathrm{W}}$ & $\mathrm{m}^{3} \mathrm{~s}^{-1}$ & volumetric flow of water jet or stream \\
\hline$S c$ & - & turbulent Schmidt number (0.9) \\
\hline$T$ & ${ }^{\circ} \mathrm{C}$ & temperature \\
\hline$t$ & $\mathrm{~s}$ & time \\
\hline$U$ & $\mathrm{~m} \mathrm{~s}^{-1}$ & superficial continuous phase velocity \\
\hline$U_{\mathrm{OF}}$ & $\mathrm{m} \mathrm{s}^{-1}$ & velocity at the water surface \\
\hline $\mathbf{U}_{r e l}$ & $\mathrm{~m} \mathrm{~s}^{-1}$ & relative velocity vector \\
\hline$U_{S}$ & $m s^{-1}$ & particle terminal or sinking velocity \\
\hline$u_{\mathrm{c}}^{\prime}$ & $\mathrm{m} \mathrm{s}^{-1}$ & continuous phase fluctuating velocity \\
\hline$V_{\mathrm{F}}$ & $\mathrm{m}^{3}$ & virtual particle volume \\
\hline$u, v, w$ & $\mathrm{~m} \mathrm{~s}^{-1}$ & velocity components \\
\hline$x, y, z$ & $\mathrm{~m}$ & co-ordinates \\
\hline$Z_{\mathrm{P}, \mathrm{B}}$ & $\mathrm{m}$ & penetration depth of the gas bubbles \\
\hline$\alpha_{\mathrm{F}}$ & - & share of fibres in virtual particle \\
\hline$\varepsilon$ & - & porosity \\
\hline$\varepsilon_{0}$ & - & porosity at zero compaction pressure \\
\hline$\varepsilon_{\min }$ & - & minimum porosity \\
\hline$\mu_{\mathrm{c}}$ & $\mathrm{kg} \mathrm{m}^{-1} \mathrm{~s}^{-1}$ & dynamic continuous phase viscosity \\
\hline$\mu_{\mathrm{m}}$ & $\mathrm{kg} \mathrm{m}^{-1} \mathrm{~s}^{-1}$ & dynamic mixture viscosity \\
\hline$\mu_{\mathrm{r}}$ & $\mathrm{kg} \mathrm{m}^{-1} \mathrm{~s}^{-1}$ & dynamic relative viscosity \\
\hline$[\mu]$ & - & intrinsic viscosity \\
\hline$v_{\mathrm{tc}}$ & $\mathrm{m}^{2} \mathrm{~s}^{-1}$ & kinematic turbulent eddy viscosity of the continuous phase \\
\hline$\rho_{\mathrm{c}}$ & $\mathrm{kg} \mathrm{m}^{-3}$ & continuous phase density \\
\hline$\rho_{\mathrm{d}}$ & $\mathrm{kg} \mathrm{m}^{-3}$ & dispersed phase density \\
\hline$\rho_{\mathrm{F}}$ & $\mathrm{kg} \mathrm{m}^{-3}$ & virtual particle density \\
\hline$\rho_{\mathrm{P}}$ & $\mathrm{kg} \mathrm{m}^{-3}$ & density of dry fibers \\
\hline$\tau_{\mathrm{c}}$ & $\mathrm{s}$ & Lagrangian turbulence time \\
\hline$\tau_{\mathrm{d}}$ & $\mathrm{s}$ & Particle relaxation time \\
\hline$\Phi$ & - & volume fraction \\
\hline$\Phi_{\mathrm{m}}$ & - & maximum volume fraction \\
\hline
\end{tabular}




\section{REFERENCES}

Batchelor, G.K., The effect of Brownian motion on the bulk stress in a suspension of spherical particles, Journal of Fluid Mechanics 83, (1977), 97-117.

Bin, A. K. (1993): Gas entrainment by plunging liquid jets, Chem. Eng. Sci. Vol. 48, pp. 3585-3630

Bonetto, F., Lahey Jr., R.T. (1993): An experimental study on air carry under due to a plunging liquid jet, Int. J. Multiphase Flow Vol. 19, No. 2, pp. 281-294

Burns, A. D., T. Frank, I. Hamill J.-M. Shi, The Favre Averaged Drag Model for Turbulent Dispersion in Eulerian Multi-Phase Flows, 5th International Conference on Multiphase Flow, ICMF'04, Yokohama, Japan, May 30-June 4, 2004, Paper No. 392.

Cummings, P.D., Chanson, H. (1997a): Air entrainment in the developing flow region of plunging jets - Part1: Theoretical Development, Transactions of the ASME, Journal of Fluids Engineering Vol. 119, pp. 597-602

Cummings, P.D., Chanson, H. (1997b): Air entrainment in the developing flow region of plunging jets - Part2: Experimental, Transactions of the ASME, Journal of Fluids Engineering Vol. 119, pp. 603608

Grahn, A.; Krepper, E.; Alt, S.; Kästner, W.: Modelling of differential pressure buildup during flow through beds of fibrous materials, Chemical Engineering and Technology 29 (2006), 997 - 1000

Haider, A., Levenspiel, O.1989, Drag coefficient and terminal velocity of spherical and non spherical particles, Powder Technology Vol. 58, 63-70

Hwang, W.; Eaton, J.K.: Turbulence attenuation by small particles in the absence of gravity, International Journal of Multiphase Flow 32, (2006), 1386-1396

Iguchi, M., Okita, K., Yamamoto, F. (1998): Mean velocity and turbulence characteristics of water flow in the bubble dispersion region induced by plunging water jet, Int. J. Multiphase Flow Vol. 24, No. 4, pp. 523-537

Krieger, L.M., T.J. Dougherty, A mechanism for non-Newtonian flow in suspensions of rigid spheres, Transactions of the Society of Rheology 3, (1959), 137-152.

Maron, S.H., P. E. Pierce, Application of Ree-Eyring generalized flow theory to suspensions of spherical particles, Journal of Colloid Science 11, (1956), 80-95.

Moraga, F.J., A.E. Larreteguy, D.A. Drew, R.T. Lahey Jr, Assessment of turbulent dispersion models for bubbly flows in the low Stokes number limit, International Journal of Multiphase Flow 29, (2003), 655-673.

Salman, A.D., Verba, A.: New approximate equations to estimate the drag coefficient of different particles of regular shape, Periodica Polytechnica of the Technical University Budapest - Chemical Engineering, Vol. 32 (1988), No. 4, pp. 261-268

Schiller, L. and Nauman, A., 1933. VDI Zeitschrift, 77 p 318

Turney, M. A., Cheung, M. K., Powell, R. L., McCarthy, M. J.: Hindered Settling of Rod-Like Particles Measured with Magnetic Resonance Imaging, AIChE Journal, Vol. 41, No. 2 (1995)

$\mathrm{Xu}$, J., S. Chatterjee, K.W. Koelling, Y. Wang, S. E. Bechtel, Shear and extensional rheology of nanocarbon fiber suspensions, Rheologica Acta 44, (2005), 537-562

\section{RELEVANT OECD REPORTS}

Knowledge Base for Emergency Core Cooling System Recirculation Reliability, NEA/CSNI/R(95)11, 1996

Knowledge Base for the Effect of Debris on Pressurized Water Reactor Emergency Core Cooling Sump Performance, NUREG/CR-6808; LA-UR-03-0880, 2003 
Knowledge Base for Strainer Clogging -- Modifications Performed in Different Countries Since 1992, NEA/CSNI/R(2002)6

Debris impact on Emergency coolant recirculation, Workshop Albuquerque, NM, USA February 2004, Proceedings OECD 2004 NEA No. 5468 